\title{
Habitat loss and human-elephant conflict in Assam, India: does a critical threshold exist?
}

\author{
Laura Chartier, Alexandra Zimmermann and Richard J. LAdLe
}

\begin{abstract}
Human-elephant conflict in India, driven by habitat loss and an expanding human population, is a complex challenge for biodiversity conservation. Determining if, how and why this conflict has changed over time will be an important step towards managing landscapes where people and elephants Elephas maximus coexist. This study combines social surveys and remote sensing data to analyse patterns in human-elephant conflict and land-use change over time. The reported experience of conflict increased dramatically in the early 1980s, with $85 \%$ of those surveyed indicating that conflict began after 1980 . The expansion of conflict showed a significant southward trend and was associated with forest cover dropping below $30-40 \%$. Based on our results we propose that a critical habitat threshold for human-elephant conflict may exist at $30-40 \%$ forest cover. Below this level, conflict expanded across the landscape. The existence of such a deforestation threshold may have important implications for landscape management in elephant range states that seek to avoid or mitigate further conflict. Maintenance of remaining forest areas, reforestation, and the creation of habitat corridors are strategies that could help prevent further expansion of conflict.
\end{abstract}

Keywords Assam, deforestation, habitat loss, habitat threshold, human-elephant conflict, human-wildlife conflict, India

This paper contains supplementary material that can be found online at http://journals.cambridge.org

\section{Introduction}

$\mathrm{T}$ he global loss of wild habitats and the expansion of human populations have intensified conflicts between people and wildlife (Hoare, 2000; Balmford \& Whitten, 2003; Dublin \& Hoare, 2004; Woodroffe et al., 2005). India provides a dramatic example of such conflict, with the human population-with an average growth rate of $2 \%$ per year

LAURA Chartier* (Corresponding author) and Richard J. LADLe School of Geography and the Environment, Oxford University, South Parks Road, Oxford, OX1 3 PS, UK. E-mail laura.chartier@gmail.com

Alexandra Zimmermann Conservation Department, North of England Zoological Society, Chester Zoo, Chester, UK, and Wildlife Conservation Research Unit, Oxford University, Tubney, UK

${ }^{*}$ Current address: 526 M St, Anchorage, AK 99501, USA

Received 18 September 2010. Revision requested 5 November 2010. Accepted 22 December 2010. between 1950 and 2000 (UN, 2004)-coming increasingly into contact with wildlife such as the Asian elephant Elephas maximus, which is categorized as Endangered on the IUCN Red List (Choudhury, 2008). Intensifying land uses have led to degradation, fragmentation and loss of elephant habitat, and have driven elephants into contact with people, particularly in cultivated areas. Conflict between elephants and people results when elephants feed on crops, destroy farms or homes, or injure or kill people, and when people retaliate against these losses (Sukumar, 1994; Inskip \& Zimmermann, 2009). Sonitpur District, in the state of Assam in north-east India, has been referred to as a ground zero for human-elephant conflict (Kvinta, 2004). An estimated $60 \%$ of the elephants in Sonitpur and adjoining districts have disappeared in the last 5 years, many from poisoning (Kushwaha \& Hazarika, 2004), and there have been many human deaths caused by elephants. Finding ways for people and elephants to coexist will, therefore, be critical to the success of conservation efforts that seek to balance the needs of people and wildlife (Adams, 2004).

Conflict between people and elephants (or humanelephant conflict, hereinafter referred to as conflict) is not a new phenomenon; records exist of elephant crop raiding in Asia as early as 300 BC (Sukumar, 1994). However, community surveys and news reports suggest that conflict has been increasing, in both frequency and intensity, in recent decades in Asia and Africa (Kvinta, 2004; Siebert, 2006; Hedges, 2007). After millennia of coexistence it seems a shift may have occurred in the human-elephant interface, perhaps in as little as a few decades (Hoare, 2000), which has driven conflict to intolerable levels. Some argue, however, that it is merely our perception of conflict that is increasing and that the conflict itself is of a similar intensity to that of the past (Lee \& Graham, 2006). Determining whether conflict has increased in recent years was one aim of this study.

The second aim was to examine when or where such an increase may have taken place by examining patterns in conflict over time. Researchers have called the identification of thresholds, or points of rapid change from one ecological condition to another, a priority for conservationists, especially in tropical areas where biodiversity is fast eroding (du Toit et al., 2004). A small additional loss of habitat, if it occurs at or near the habitat threshold for a species, can have large effects on the extinction risk of a population (Andren, 1994; With \& Crist, 1995; Fahrig, 2001; Huggett, 2005) and is therefore of particular concern for the management of threatened species. 
When Hoare \& du Toit (1999) examined the relationship between human density and elephant density, they found a threshold pattern: at c. 15 people $\mathrm{km}^{-2}$, representing a transformation of land use to c. $40-50 \%$ human activity, elephants disappeared from the landscape (Hoare \& du Toit, 1999). If a tipping point or other important pattern is evident in the relationship between habitat and level of conflict this could serve as a management guideline, target for restoration, or early warning system for regions with large areas of remaining elephant habitat (Huggett, 2005; Rhodes et al., 2008). Although researchers have repeatedly expressed concern about a threshold in people's tolerance for elephants (Sukumar, 1995), to our knowledge this is the first study to apply the concept of a habitat threshold to the level of human-elephant conflict itself.

\section{Study area}

North-east India is one of the largest remaining strongholds for the Asian elephant, with an estimated population of 9,200-11,000 (Kushwaha \& Hazarika, 2004). Many of these elephants are in the state of Assam (Choudhury, 1999; Sukumar, 2006). Our study site in Sonitpur District, central Assam, fits the criteria given by Woodroffe et al. (2005) for high conflict areas: a highly productive area where reserves are located near cultivated lands with a high population density. The human population of the study area is c. 500,000 (Census of India, 2001), with a density of c. 440 people $\mathrm{km}^{-2}$. Sonitpur holds an estimated 100-200 elephants (Swargonari, 2003), and the study site size of c. $1,175 \mathrm{~km}^{2}$ (S. Wilson, pers. comm., 2008) is similar to that of a study elsewhere in India examining elephant behaviour in several clans of 50-200 elephants, which used a study site size of $1,130 \mathrm{~km}^{2}$ (Sukumar, 1989).

The study site (Fig. 1) is bordered to the south by the Brahmaputra River, to the east by the Bhareli River, to the west by the Gabharu River, and by forest to the north. Elephant movement is restricted to the south by the Brahmaputra and to the north by the Himalayan foothills, although elephants can cross the rivers to the east and west. An estimated four to five elephant herds return to this area on a seasonal basis (N. Hazarika, pers. comm., 2008), moving between the foothills and the Brahmaputra between October and December before returning to two forest areas in the north: Sonai Rupai Wildlife Sanctuary and Nameri National Park (D. Das, pers. comm., 2008; N. Hazarika, pers. comm., 2008; S. Wilson et al., unpubl. data).

\section{Methods}

Because reliable long-term data on land use or conflict in the state of Assam are unavailable we reconstructed the history of conflict by overlaying two data sources: social surveys and remote sensing. Sixty-six semi-structured

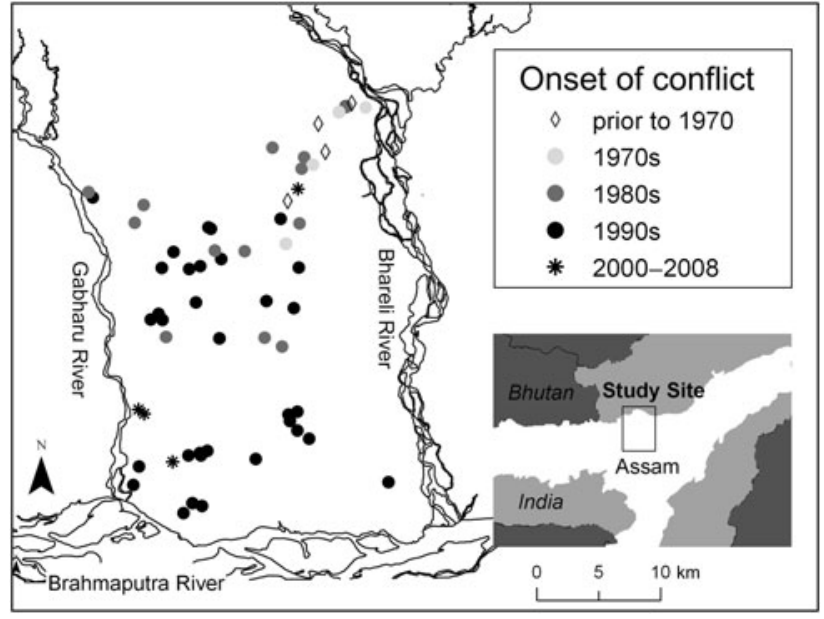

Fig. 1 Study site and spatial patterns in the reported onset of conflict. Locations of interviews are identified according to the time period in which interviewees reported the onset of conflict. The rectangle on the inset indicates the location of the main map in Sonitpur District, central Assam, India.

interviews in 52 villages were conducted in June 2008. Interviews, which were based on an open-ended questionnaire (Appendix) piloted beforehand, were conducted in Assamese by a local translator accompanied by LC. Target subjects for interviews were community members age 50 and over, preferably gaonbura (village leaders) and village elders, who would have historical knowledge of conflict. The spatial sampling frame was divided into the 16 monitoring blocks of the Assam Haathi Project (a community-based humanelephant conflict mediation project), with a target of three to five interviews in each block. Interviewees were selected through a snowballing process (Henry, 1990) based on the knowledge of Assam Haathi Project field assistants. Surveys were undertaken in all 16 sampling blocks, which cover the entirety of the study area. Because conflict with elephants, through crop raids, damage to homes and other incidents, is known to occur throughout the study area, we selected interviewees by age (the oldest in each block) rather than by experience of conflict (or lack thereof). Locations of each village were recorded with a global positioning system at the time of interviews and mapped using ArcGIS v. 9.o (ESRI, Redlands, USA). Statistical analysis of survey data was performed in SPSS v. 14 (SPSS, Chicago, USA). A segmented regression was fitted in $R$ v. 2.12 (R Development Core Team, 2010), using the segmented package (Muggeo, 2008).

We used classified satellite imagery to examine land use change in the years 1973, 1988, 2001 and 2007 based on Landsat imagery availability in the first year it existed, 1973, and availability at approximately 5-10 year intervals thereafter, as well as overall for the 34-year period from 1973 to 2007. Because of complications such as the limited availability of cloud-free data in this geography, supervised classification by a local expert resident in the region was chosen as the most accurate method of classification. 


\section{Results}

The average age of interview respondents was 58, with the oldest being two 90-year-old respondents. All reported problems with elephants. Agriculture was the primary reported occupation of $42 \%$ of the interview respondents, although all but one were involved in some form of cultivation and reported growing paddy rice as a primary crop; 92\% also had homestead gardens, in which crops favoured by elephants include jackfruit, banana, pumpkin and sugar cane. Reported problems caused by elephants included damaging or destroying homes and/or crops, killing people or cattle, raiding rice paddies and gardens, eating from fruit trees, raiding food stores and raiding for rice beer or salt.

The earliest reported year of the onset of problems with elephants was 1938 (Fig. 2). The occurrence of reported conflict increased sharply after the early 1980 s, with $85 \%$ of respondents claiming that the problems with elephants began in 1982 or later. Although some people remembered seeing elephants many years ago or in childhood, only $12 \%$ of interviewees reported that conflict began prior to 1980 ; $100 \%$ of those surveyed claimed that their village had experienced the onset of conflict by or in 2004 .

A segmented regression was fitted to the cumulative number of interviewees experiencing conflict in a given year (Fig. 2) and was found to be a better fit than a linear model (determined by a lower Akaike's information criterion). The break-point estimate in the segmented regression was 1982 (Fig. 2), with a 95\% confidence interval of 1980-1983.

All villages that claimed the conflict had begun prior to the 1980 s were in the north-east of the study site (Fig. 1). By 1988 the reported conflict had expanded southward and westward, a pattern that continued to 2004. This spatial pattern of conflict spreading southward over time (Fig. 1) is

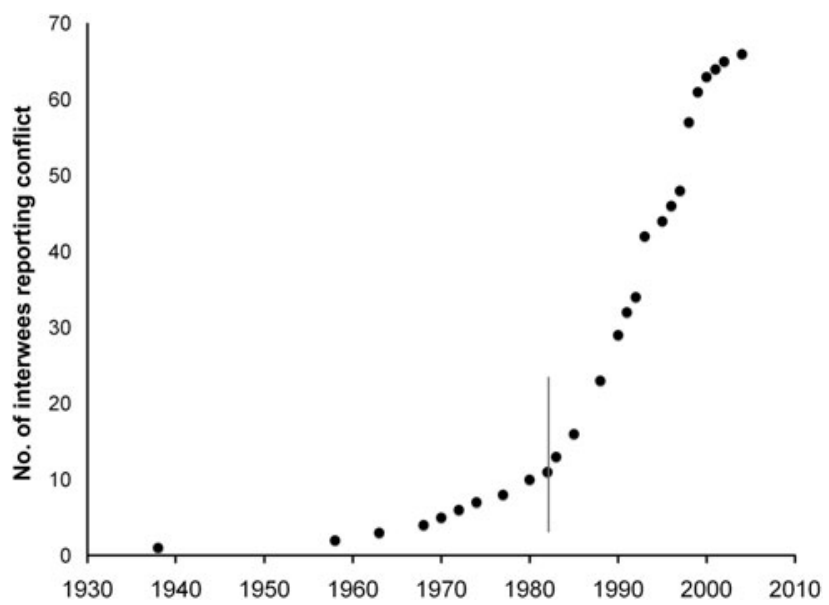

FIG. 2 Cumulative number of respondents reporting the experience of conflict in each of the years shown. Interviewees are included in the count beginning with the year they reported conflict starting. A segmented regression was fitted to these data and the break-point, at 1982 , is marked. supported by a highly significant positive correlation between an interview's latitude and the number of years of conflict reported ( $r h o=0.640, \mathrm{n}=66, \mathrm{P}<0.001$ ). More northern villages were more likely to have experienced the conflict earlier and longer than those in the south.

In the classified image analysis forest cover decreased most visibly in the northern part of the study area. Total forest cover (we use the term forest to refer to nondegraded forest types; total forest cover was calculated by adding semi-evergreen and mixed moist deciduous forest types) fell from $43 \%$ in 1973 to $16 \%$ in 2007 (Fig. 3). Degraded forest increased overall from $9 \%$ in 1973 to $30 \%$ in 2007 , while crop land increased from 28 to $33 \%$ and tea plantations (known locally as tea gardens) increased from 14 to $15 \%$ (Fig. 3 ).

There was a highly significant negative correlation between percentage of total forest cover and percentage of total survey villages reporting the onset of conflict (rho $=-0.999, \mathrm{n}=4, \mathrm{P} \leq 0.001$ ) and a highly significant correlation between the percentage of total villages reporting conflict and the percentage of total degraded forest cover ( $\mathrm{rho}=0.993, \mathrm{n}=4, \mathrm{P}=0.007$ ).

A small amount of forest loss preceded the 1982 breakpoint and subsequent increase in the number of interviewees reporting the onset of conflict. By 1988 forest cover had fallen to $37 \%$ (from $43 \%$ in 1973). With deforestation being by far the largest change in land use during the period studied we propose that a critical threshold may have been crossed somewhere between 30 and $40 \%$ forest cover, precipitating a spread of conflict that continued from that point onward (Fig. 4).

\section{Discussion}

This study demonstrates that the spatial extent of humanelephant conflict in Sonitpur increased between 1938 and

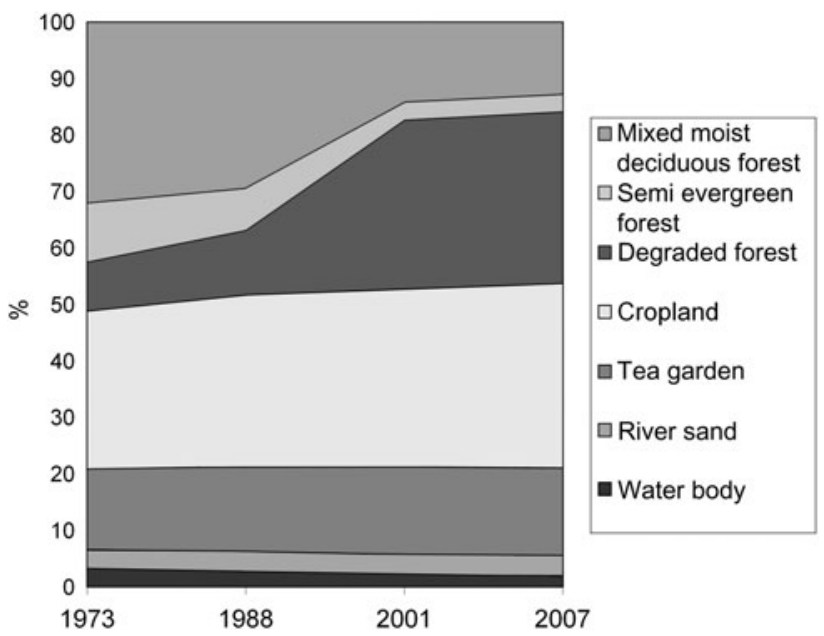

FIG. 3 Percentage of total land area by major land-use category, 1973-2007. 


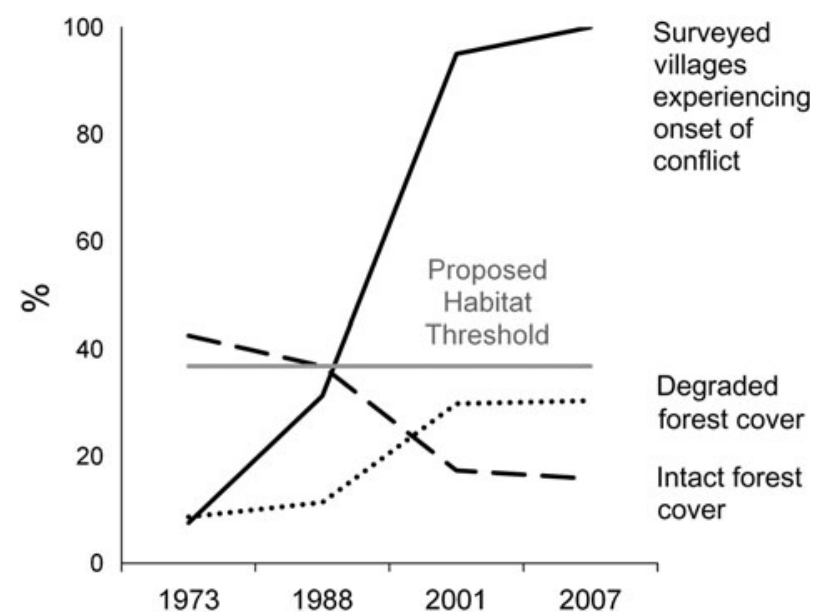

FIG. 4 Trends in habitat loss and human-elephant conflict. The percentage total intact forest cover, percentage total degraded forest cover and percentage total surveyed villages claiming to experience the onset of conflict in each of the years are shown. The proposed conflict threshold, in grey, is at c. $37 \%$ forest cover.

2008. The spread of conflict followed a southward pattern over time (Fig. 1), with northern villages experiencing conflict the longest. The most dramatic degradation of forest habitat between 1973 and 2007 occurred in this same northern area, near the Himalayan foothills. Other land uses changed little over time: crop land increased only $5 \%$ from 1973 to 2007 , and tea plantations (used by elephants for shade) increased only $1 \%$ over that time. Because the quality of Landsat imagery differed slightly in different years, with 1973 being coarser than subsequent imagery, and because much of the land area (for example tea plantations) changed little, we examined overall trends of change by area over time. Forest habitat loss, and conversion to degraded forest, was by far the largest change.

One possible explanation for the observed spread of conflict is that forest habitat in the north may have been sufficient to minimize conflict prior to the early 1980s. A segmented regression, a relatively recent approach for detecting ecological thresholds that has been used elsewhere (Betts et al., 2007), indicated a break-point in the reported onset of conflict at 1982 (Fig. 2). This suggests an abrupt shift rather than a gradual change in the level of conflict.

Although determining the time lag between loss of forest cover and expansion of conflict is an inference at best, the transition of conflict from a low level (pre-1980) to a widespread extent ( $85 \%$ of respondents experiencing onset of conflict in 1982 or later) appears to have occurred within a decade, following a relatively small loss of forest cover. The results of this study therefore suggest that a critical threshold for conflict may exist between 30 and $40 \%$ forest cover. Once forest habitat fell below this level, conflict expanded from a few affected villages to the majority of those surveyed.

This proposed threshold of $30-40 \%$ is similar to habitat thresholds identified by other studies. For example, Andren (1994) estimated that the effects of habitat fragmentation are compounded below 30\% habitat, and With \& Christ (1995) found that organisms with good dispersal become patchily distributed when their preferred habitat is less than $35-40 \%$ of the landscape. Hoare \& du Toit (1999) found that an overall transition of land uses to $40-50 \%$ human activity negatively affected elephants. In our study area deforestation was the overriding change in land use. However, land-use changes prior to when remotely sensed imagery became available in 1973 may also have played a role in future conflict.

Many factors other than land-use change influence conflict, including elephant behaviour, human attitudes, and management tactics (Hoare, 2000; Dublin \& Hoare, 2004). Research in other regions has shown that conflict has become more widespread but not necessarily more intense than in the past (Hoare, 1999; O'Connell-Rodwell et al., 2000), which may be the case in Assam. The number of human and elephant deaths is difficult to calculate accurately in Assam because records are incomplete. Data on human and elephant deaths, from the Forest Department in Sonitpur, were available only from 1997 (Divisional Forest Officer, Sonitpur West Division, pers. comm., 2008). From 1997 to 2007, 89 human deaths, and 69 elephant deaths not defined as natural, were recorded. Because conflict reports are inconsistently recorded during and between years, using them to measure changes in intensity is problematic.

We used interview-based methods to reconstruct patterns in conflict over time because such long-term data were unavailable. However, interview-based assessments present a number of challenges. A person's memory of when an incident occurred may be mistaken (Hedges, 2007) and farmers have a noted tendency to exaggerate when discussing human-wildlife conflict (Naughton-Treves \& Treves, 2005). Although species such as primates or insects often cause more total damage than elephants, the response to them is less intense (Hedges et al., 2005; Hedges, 2007). Elephant damage is locally catastrophic (Woodroffe et al., 2005) and the costs borne by an individual can be extremely high (Balmford \& Whitten, 2003). Such factors can contribute to a distorted perception of conflict (Inskip \& Zimmermann, 2009). We attempted to mitigate this issue by conducting interviews in the summer, the lowest conflict season of the year, when responses could perhaps be more objective than when conflict is at its height (during the paddy harvest).

Despite these challenges, the social survey data yielded important insights. The spatial extent of conflict expanded over time, and the abrupt increase in the number of people experiencing conflict in the early 1980 s, following a small level of forest loss, suggests the possibility of a threshold 
change. There is uncertainty in threshold estimates and a need for more statistical rigour (Walker \& Meyers, 2004; Huggett, 2005; Lindenmayer et al., 2005). As our study was limited by the number of years of satellite imagery available for the study site, replicating this research in areas where more years of land-use data are available would be a good test of the $30-40 \%$ habitat threshold.

The underlying mechanism of this potential threshold also deserves further study. Hoare (2000) argues that elephant raids on crops are explained by optimal foraging theory. Crops can be more nutritious than wild plants, and elephants can obtain their daily food requirement in less time by eating crops rather than wild plants (Sukumar, 1994). Santiapillai \& Read (2010) suggested that elephants may be responding to olfactory signals in timing their raids to coincide with the ripening of rice. A study now underway in our study area, conducted by the Assam Haathi Project, is examining the question of whether conflict is driven by resource preferences, nutritional needs, or other factors (for example, a need for minerals such as salt may explain elephant raids on homes) and will provide insight into the proposed threshold.

This proposed threshold at $30-40 \%$ forest cover may contribute to an understanding of management needs for maintaining landscapes where both people and elephants can thrive. Countries with large areas of remaining elephant habitat, such as Cambodia, Myanmar and Malaysia, may seek to avoid crossing a conflict threshold. In Sonitpur a key step towards mitigating conflict will be to maintain the integrity of existing forest reserves in Sonitpur (Sonai Rupai and Nameri) and prevent further encroachment. The role of the habitat matrix in mitigating conflict, not examined here, also deserves further study.

Nationwide in India, however, there is a promising trend: forest area is increasing (FAO, 2009). This could help avoid increases in conflict, and even reduce conflict, depending on the quality of reforested areas. Human land uses make the creation of new reserves impractical in many areas and new protected areas alone would not be sufficient (Nyhus \& Tilson, 2004); already $70 \%$ of the Asian elephant's range is outside protected areas (Choudhury, 1999). We will need to find ways to help elephants use existing habitats, inside and outside protected areas, without causing harm to humans. Electric fencing has met with success in some human-elephant conflict regions (O'ConnellRodwell et al., 2000), as have traditional agricultural techniques (Fernando et al., 2005).

However, in Sonitpur, such deterrents frequently result in a spatial reshuffling of conflict rather than its long-term elimination. Longer term and larger scale solutions are needed to lessen impacts on local residents. Habitat corridors are one option, linking existing reserves or forest areas through reforestation or other changes in land use, which could allow elephants to move along their traditional migration routes and minimize the spread of conflict. But Sonitpur also demonstrates that forest cover is not the sole factor determining elephant persistence. The attitudes and tolerance of people in Assam and elsewhere remain central to the search for ways to allow people and elephants to share the landscape.

\section{Acknowledgements}

This project was undertaken in collaboration with the Assam Haathi Project, an initiative of Chester Zoo and EcoSystems-India, funded by the UK Darwin Initiative. Assistance with field logistics and Assamese-English interpretation was provided by Nandita Hazarika, Dhruba Jyoti Das, Bhaben Hazarika, Lakhi Kumar Nath, Uttam Roy and Pallab Baruah. Classified maps were commissioned from the Assamese non-profit Aaranyak and created by Pranjit Kumar Sarma. We thank Nandita Hazarika and Scott Wilson for their support, Marcus Geist and Rowan Trebilco for their assistance, and those who provided helpful comments on this article, including The Nature Conservancy employees and two anonymous reviewers.

\section{References}

Adams, W.M. (2004) Against Extinction: The Story of Conservation. Earthscan, London, UK.

Andren, H. (1994) Effects of habitat fragmentation on birds and mammals in landscapes with different proportions of suitable habitat: a review. Oikos, 71, 355-366.

Balmford, A. \& Whitten, T. (2003) Who should pay for tropical conservation, and how could the costs be met? Oryx, 37, 238-250.

Betts, M.G., Forbes, G.J. \& Diamond, A.W. (2007) Thresholds in songbird occurrence in relation to landscape structure. Conservation Biology, 21, 1046-1058.

Census of India (2001) Census of India. Office of the Registrar General, Government of India, New Delhi, India.

Choudhury, A. (1999) Status and conservation of the Asian elephant Elephas maximus in north-eastern India. Mammal Review, 29, 141-174.

Choudhury, A., Lahiri Choudhury, D.K., Desai, A., Duckworth, J.W., Easa, P.S., Johnsingh, A.J.T. et al. (2008) Elephas maximus. In IUCN Red List of Threatened Species v. 2010.4. Http://www.iucnredlist.org [accessed 2 May 2011].

Dublin, H.T. \& Hoare, R.E. (2004) Searching for solutions: the evolution of an integrated approach to understanding and mitigating human-elephant conflict in Africa. Human Dimensions of Wildlife, 9, 271-278.

Du Toit, J.T., Walker, B.H. \& Campbell, B.M. (2004) Conserving tropical nature: current challenges for ecologists. Trends in Ecology \& Evolution, 19, 12-17.

FAHrig, L. (2001) How much habitat is enough? Biological Conservation, 100, 65-74.

FAO (Food and Agriculture Organization) (2009) State of the World's Forests 2009. Food and Agriculture Organization of the United Nations, Rome, Italy.

Fernando, P., Wikramanayake, E., Weerakoon, D., Jayasinghe, L.K.A., Gunawardene, M. \& Janaka, H.K. 
(2005) Perceptions and patterns of human-elephant conflict in old and new settlements in Sri Lanka: insights for mitigation and management. Biodiversity and Conservation, 14, 2465-2481.

Hedges, S. (2007) Commentary. Gajah, 26, 43-46.

Hedges, S., Tyson, M.J., Sitompul, A.F., Kinnaird, M.F., Gunaryadi, D. \& Aslan (2005) Distribution, status, and conservation needs of Asian elephants (Elephas maximus) in Lampung province, Sumatra, Indonesia. Biological Conservation, $124,35-48$.

Henry, G.T. (1990) Practical Sampling. Sage Publications, Newbury Park, USA.

Hoare, R.E. (1999) Determinants of human-elephant conflict in a land-use mosaic. Journal of Applied Ecology, 36, 689-700.

Hoare, R.E. (2000) African elephants and humans in conflict: the outlook for co-existence. Oryx, 34, 34-38.

Hoare, R.E. \& DU Toit, J.T. (1999) Coexistence between people and elephants in African savannas. Conservation Biology, 13, 633-639.

Huggett, A.J. (2005) The concept and utility of 'ecological thresholds' in biodiversity conservation. Biological Conservation, 124, 301-310.

InSKip, C. \& Zimmermann, A. (2009) Human-felid conflict: a review of patterns and priorities worldwide. Oryx, 43, 18-34.

Kushwaha, S.P.S. \& Hazarika, R. (2004) Assessment of habitat loss in Kameng and Sonitpur Elephant Reserves. Current Science, $87,1447-1453$.

Kvinta, P. (2004) Stomping grounds. In National Geographic Adventure, National Geographic, August 2004, 67-71.

Lee, P. \& Graham, M.D. (2006) African elephants and humanelephant interactions: implications for conservation. International Zoo Yearbook, 40, 9-19.

Lindenmayer, D.B., Fischer, J. \& Cunningham, R.B. (2005) Native vegetation cover thresholds associated with species responses. Biological Conservation, 124, 311-316.

Muggeo, V.M.R. (2008) Segmented: an R package to fit regression models with broken-line relationships. $R$ News, 8, 20-25. Http:// cran.r-project.org/doc/Rnews/ [accessed 13 December 2010].

Naughton-Treves, L. \& Treves, A. (2005) Socio-ecological factors shaping local support for wildlife: crop-raiding by elephants and other wildlife in Africa. In People and Wildlife, Conflict or Co-existence? (eds R. Woodroffe, S. Thirgood \& A. Rabinowitz), pp. 252-277. Cambridge University Press, Cambridge, UK.

Nyhus, P. \& Tilson, R. (2004) Agroforestry, elephants, and tigers: balancing conservation theory and practice in human-dominated landscapes of South-east Asia. Agriculture Ecosystems \& Environment, 104, 87-97.

O’Connell-Rodwell, C.E., Rodwell, T., Rice, M. \& Hart, L.A. (2000) Living with the modern conservation paradigm: can agricultural communities co-exist with elephants? A five-year case study in East Caprivi, Namibia. Biological Conservation, 93, 381-391.

R Development Core Team (2010) R: A Language and Environment for Statistical Computing. R Foundation for Statistical Computing, Vienna, Austria. Http://www.R-project.org [accessed 5 December 2010].

Rhodes, J.R., Callaghan, J.G., McAlpine, C.A., De Jong, C., Bowen, M.E., Mitchell, D.L. et al. (2008) Regional variation in habitat-occupancy thresholds: a warning for conservation planning. Journal of Applied Ecology, 45, 549-557.

Santiapillai, C. \& Read, B. (2010) Would masking the smell of ripening paddy-fields help mitigate human-elephant conflict in Sri Lanka? Oryx, 44, 509-511.

Siebert, C. (2006) An elephant crackup? New York Times Magazine 8 October 2006. Http://www.nytimes.com/2006/10/o8/magazine/ o8elephant.html [accessed 1o August 2010].

SukUmar, R. (1989) Ecology of the Asian elephant in southern India. 1. Movement and habitat utilization patterns. Journal of Tropical Ecology, 5, 1-18.

Sukumar, R. (1994) Elephant Days and Nights. Oxford University Press, New York, USA.

Sukumar, R. (1995) Elephant raiders and rogues-the more Asian elephants raid crop fields, the more the farmers' traditional tolerance is put to the test. Natural History, 104, 52-61.

SUKUMAR, R. (2006) A brief review of the status, distribution and biology of wild Asian elephants Elephas maximus. International Zoo Yearbook, 40, 1-8.

Swargonari, A. (2003) Sonitpur West Division Report. S.W. Division, Tezpur, India.

UN (United Nations) (2004) World Population to 2300. Department of Economic and Social Affairs, Population Division, United Nations, New York, USA.

Walker, B. \& Meyers, J.A. (2004) Thresholds in ecological and social-ecological systems: a developing database. Ecology and Society, 9, 3 .

With, K.A. \& CRIST, T.O. (1995) Critical thresholds in species responses to landscape structure. Ecology, 76, 2446-2459.

Woodroffe, R., Thirgood, S. \& Rabinowitz, A. (eds) (2005) People and Wildlife: Conflict or Coexistence? Cambridge University Press, Cambridge, UK.

\section{Appendix}

The appendix for this article is available online at http:// journals.cambridge.org

\section{Biographical sketches}

LAURA CHARTIER has research interests that include human-wildlife dynamics, ecological thresholds and the dynamics of large-scale landscapes and seascapes. She currently works on climate change and marine conservation issues. Alexandra Zimmermann works on human-wildlife conflict issues. After studying human-jaguar conflict in Brazil and founding the Assam Haathi Project for human-elephant conflict mitigation in India, her research now focuses on conflict dynamics and models for best practice in conflict mitigation. RICHARD LADLE has diverse and interdisciplinary research interests that span wildlife conflict, extinction theory, conservation biogeography, conservation communication and public representation, and theoretical ecology. 